\title{
Detection of Chlorophyll Fluorescence in Vegetation from Airborne Hyperspectral CASI Imagery in the Red Edge Spectral Region
}

\author{
Zarco-Tejada $^{1}$, P.J., J.R. Miller ${ }^{2}$, D. Haboudane ${ }^{3}$, N. Tremblay ${ }^{4}$, and S. Apostol ${ }^{5}$ \\ ${ }^{1}$ Grupo de Óptica Atmosférica (GOA-UVA), Universidad de Valladolid, Spain - pzarco@iaf.uva.es \\ 2 Department of Physics and Astronomy, York University, Toronto, Canada. \\ ${ }^{3}$ Département des Sciences Humaines, Université du Québec à Chicoutimi Québec, Canada. \\ ${ }^{4}$ Agriculture \& Agri-Food Canada, St. Jean sur Richelieu, Québec, Canada. \\ ${ }^{5}$ Physics Department, Faculty of Sciences, Valahia University, 24 Bd. Unirii, 0200 Targoviste, Romania.
}

\begin{abstract}
This work provides a description of the investigations conducted to assess the detection of chlorophyll fluorescence from hyperspectral CASI data. The viability of retrieval of solarinduced fluorescence through airborne imaging spectrometer measurements of radiance of targets under natural illumination is studied. A method based on in-filling of fluorescence signals in atmospheric oxygen absorption lines is applied to study sites of corn crop grown under different stress conditions due to variations in nitrogen treatment. Results of the relationships found between measurements of laser-induced fluorescence and chlorophyll concentration at the ground level with the in-filling of the $762 \mathrm{~nm}$ oxygen band and optical indices calculated from CASI imagery $R_{685} / R_{655}$, derivative $D_{730} / D_{706}$, and the doublepeak derivative reflectance index $\mathrm{DPi}\left(\mathrm{D}_{688} \cdot \mathrm{D}_{710}\right) / \mathrm{D}_{697}{ }^{2}$ are presented.
\end{abstract}

Keywords-chlorophyll fluorescence; in-filling; hyperspectral; double-peak; red-edge

\section{INTRODUCTION}

Remote detection of solar-induced chlorophyll fluorescence (CF) in vegetation focuses on methods based on the calculation of optical indices, derivative analysis and spectral subtraction. Solar-induced natural fluorescence detection in vegetation was reported by McFarlane et al. [1] using the H- $\alpha$ Fraunhofer line at $656 \mathrm{~nm}$, and Carter et al. [2] using the $\mathrm{H}-\alpha$ and $\mathrm{O}_{2}-\mathrm{B}$ lines in leaf measurements. Buschmann and Lichtenthaler [3] provided evidence of fluorescence on leaf reflectance signatures, with additional studies suggesting the effect of fluorescence on apparent reflectance. Zarco-Tejada et al. [4] developed a leaflevel model (FRT) to account for the effects of chlorophyll fluorescence on the leaf apparent reflectance. Subsequent studies demonstrated that CF could be detected at both leaf and canopy levels using light induction with cut-off filters, timedecay experiments, reflectance difference calculations and optical indices from reflectance spectra, observing its effects on the red edge spectral region [5]. Recently, Maier et al. [6] has shown results suggesting that the in-filling of atmospheric oxygen absorption bands in the $762 \mathrm{~nm}$ region can be detected in the radiance spectra observed by airborne imaging spectrometers to calculate the fluorescence signal at such spectral band. In this research, different analysis methods based on red-edge reflectance optical indices and on in-filling of chlorophyll fluorescence on the radiance signal are applied to study-sites of corn crop grown under different stress conditions where ground-truth fluorescence and airborne hyperspectral imagery was collected with the Compact Airborne Spectrographic Imager (CASI).

\section{DATA COLLECTION}

The study area used is an experimental site of the GEOmatics for Informed Decisions (GEOIDE) project, Agriculture and Agri-Food Canada, in Quebec, Canada. Corn was grown on four adjacent experimental fields with four experimental blocks, each containing four $20 \times 20 \mathrm{~m}$ plots of 27 rows, to which nitrogen fertilizer treatments were randomly assigned, with no fertilization, intermediate fertilization with uniform nitrogen application at top dressing, variable nitrogen application at top dressing, and over-fertilization, resulting in randomly-distributed plots under different stress conditions. Hyperspectral images were acquired by the airborne CASI sensor during summer 2000 (Fig. 1). Ground truth measurements included (i) leaf sampling for determination of leaf chlorophyll content $\left(\mathrm{C}_{\mathrm{ab}}\right)$; (ii) corn leaf reflectance and transmittance measurements using integrating sphere and spectrometer, (iii) LAI measurements using the LAI-2000 instrument, and (iv) crop growth measures. Leaf samples from 4 plants per experimental unit were used for analysis of $\mathrm{C}_{\mathrm{ab}}$. Laser-induced fluorescence emission spectra at wavelengths 308, 360, 440, 480 and $630 \mathrm{~nm}$ were obtained using a compact multi-wavelength Fluorescent Lidar System model PL (FLSPL) prototype [7]. CASI airborne images were collected using a multispectral mode of operation, with $1 \mathrm{~m}$ spatial resolution and 7 spectral bands, and a hyperspectral mode, with $2 \mathrm{~m}$ spatial resolution and 72 channels covering the spectral range 408 to $947 \mathrm{~nm}$. The processing of CASI imagery included radiance calibration, atmospheric corrections and reflectance retrieval, removal of aircraft motion, geo-referencing, and flat field spectral anomaly removal. 


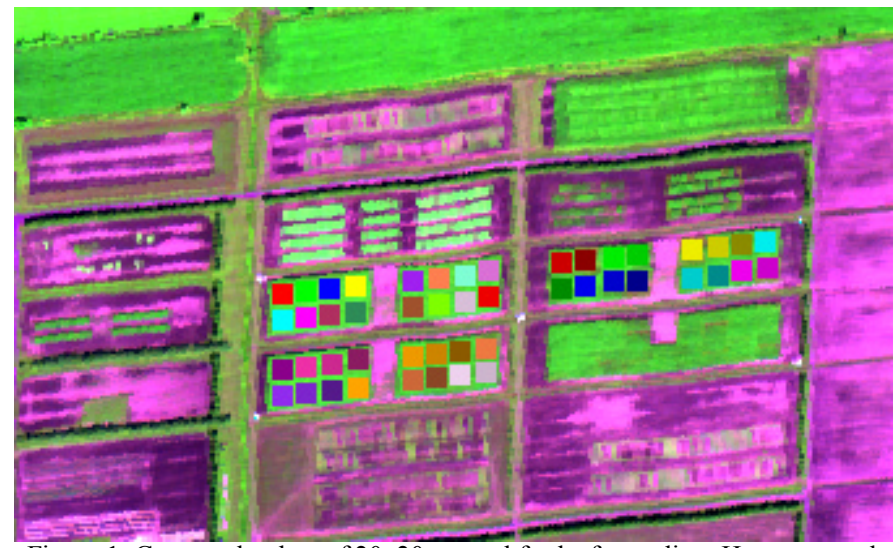

Figure 1. Corn study plots of $20 \times 20 \mathrm{~m}$ used for leaf sampling. Hyperspectral CASI image of 72 bands and $2 \mathrm{~m}$ spatial resolution.

\section{METHODS}

\section{A. Fluorescence Detection with Optical Indices}

Optical indices related to chlorophyll fluorescence detection introduced from previous research [4,5], such as $\left(\mathrm{R}_{675} \cdot \mathrm{R}_{690}\right) / \mathrm{R}_{683}{ }^{2}, \mathrm{R}_{685} / \mathrm{R}_{655}, \mathrm{D}_{730} / \mathrm{D}_{706}$, and the double-peak derivative reflectance index DPi $\left(\mathrm{D}_{688} \cdot \mathrm{D}_{710}\right) / \mathrm{D}_{697}{ }^{2}$ were calculated from CASI reflectance data extracted from each of the 48 plots used in this study.

\section{B. Fluorescence in-filling at Oxygen Absorption Lines}

The method for far-field fluorescence detection through infilling at the 690 and $762 \mathrm{~nm}$ oxygen bands require the variables shown in Figure 2 for the radiation flow [6]. The influence of atmospheric transmittance between the target and the sensor along the view direction $\left(\mathrm{T}_{\mathrm{v}}\right)$ and the path radiance $\left(\mathrm{L}_{\text {path }}\right)$ are included.
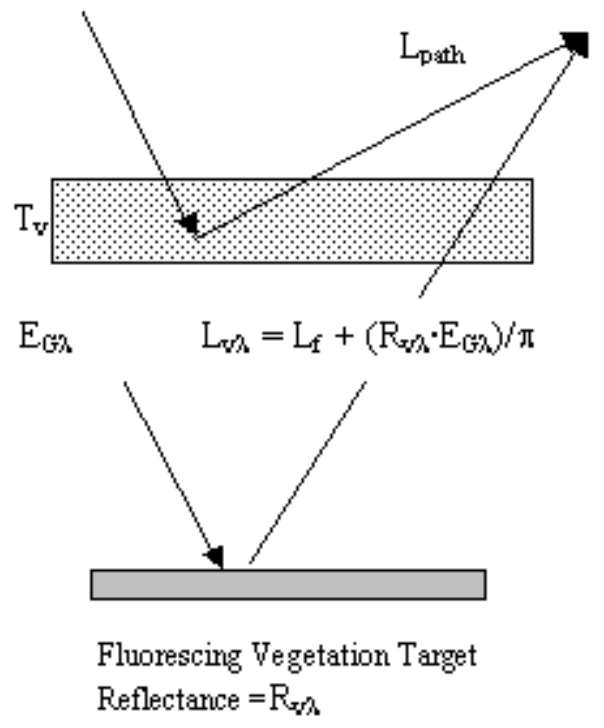

Figure 2. Schematic view of the radiation flow for far-field fluorescence detection in vegetation targets.
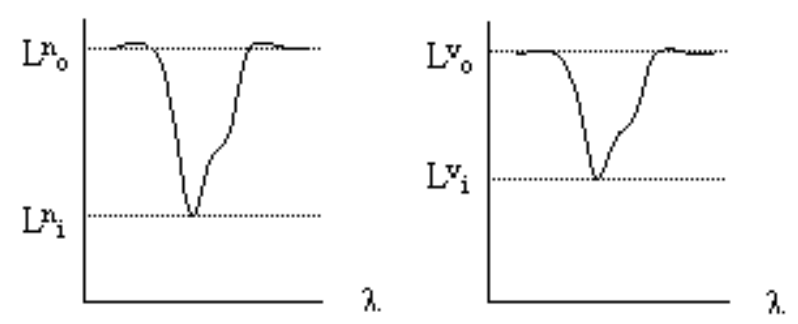

Figure 3. Radiance of non-fluorescing (left) and fluorescing (right) targets at the $762 \mathrm{~nm}$ oxygen absorption band.

The radiance outside and in the 762 oxygen absorption feature for non-fluorescing targets $\left(L_{o}^{n}, L_{i}^{n}\right)$ (Fig. 3) is defined as,

$$
\begin{aligned}
& L_{o}^{n}=\left(\frac{R_{n} E_{G o}}{\pi}\right) T_{V o}+L_{o}^{\text {path }} \\
& L_{i}^{n}=\left(\frac{R_{n} E_{G i}}{\pi}\right) T_{V i}+L_{i}^{\text {path }}
\end{aligned}
$$

with the relation between $L_{i}^{n}$ and $L_{o}^{n}$ as,

$$
L_{i}^{n}=k_{1} \cdot L_{o}^{n}+k_{2}
$$

where,

$$
k_{1}=\frac{T_{V i}}{T_{V o}} \frac{E_{G i}}{E_{G o}} ; k_{2}=L_{i}^{\text {path }}-k_{1} \cdot L_{o}^{\text {path }}
$$

In the case of fluorescing targets, such as vegetation, the radiance outside and in the oxygen absorption band are,

$$
\begin{aligned}
& L_{o}^{v}=\left(\frac{R_{v} E_{G o}}{\pi}+L_{f}\right) \cdot T_{V o}+L_{o}^{\text {path }} \\
& L_{i}^{v}=\left(\frac{R_{v} E_{G i}}{\pi}+L_{f}\right) \cdot T_{V i}+L_{i}^{\text {path }}
\end{aligned}
$$

with the relation between $L_{i}^{v}$ and $L_{o}^{v}$ as,

$$
L_{i}^{V}-k_{3} \cdot L_{f}=k_{1} \cdot L_{o}^{V}+k_{2}
$$

where $k_{1}$ and $k_{2}$ are as in (4) and,

$$
k_{3}=T_{V i}-k_{1} \cdot T_{v o}
$$

Therefore, coefficients $k_{1}$ and $k_{2}$ can be calculated from (3) using a set of non-fluorescing targets, enabling the calculation of fluorescence $L_{f}$ from (7) for fluorescing targets, such as vegetation. This method was applied to hyperspectral imagery collected with the airborne CASI sensor. 


\section{RESULTS}

The methodology described above was applied to all scene pixels of the $7.5 \mathrm{~nm}$ spectral bandwidth CASI image collected over the experimental site. Fluorescence in-filling calculations were performed for both 690 and $762 \mathrm{~nm}$ oxygen absorption features. The bands for the in and outside radiances were, for the $762 \mathrm{~nm}$ oxygen absorption, $L_{i}=762 \mathrm{~nm} ; L_{o}=754 \mathrm{~nm}$; and for the $690 \mathrm{~nm}$ oxygen absorption, $L_{i}=693 \mathrm{~nm} ; L_{o}=678 \mathrm{~nm}$. Figure 4 shows $k_{1}$ and $k_{2}$ coefficient calculations using nonfluorescing pixels for the $762 \mathrm{~nm}$ oxygen band (top left) and $690 \mathrm{~nm}$ band (top right). The fluorescence calculation of nonvegetation and vegetation pixels for the $762 \mathrm{~nm}$ and $690 \mathrm{~nm}$ regions shows higher fluorescence for vegetation pixels, as expected (Fig. 4, middle left and right). This method was then applied to the spectra from the 48 study plots under different stress conditions (Fig. 4, bottom left and right), and fluorescence estimation at both 762 and $690 \mathrm{~nm}$ region. Fluorescence estimates and optical indices calculated from the CASI reflectance at the study plots were correlated with leaflevel fluorescence data measured with the compact multiwavelength Fluorescent Lidar System (Table I).
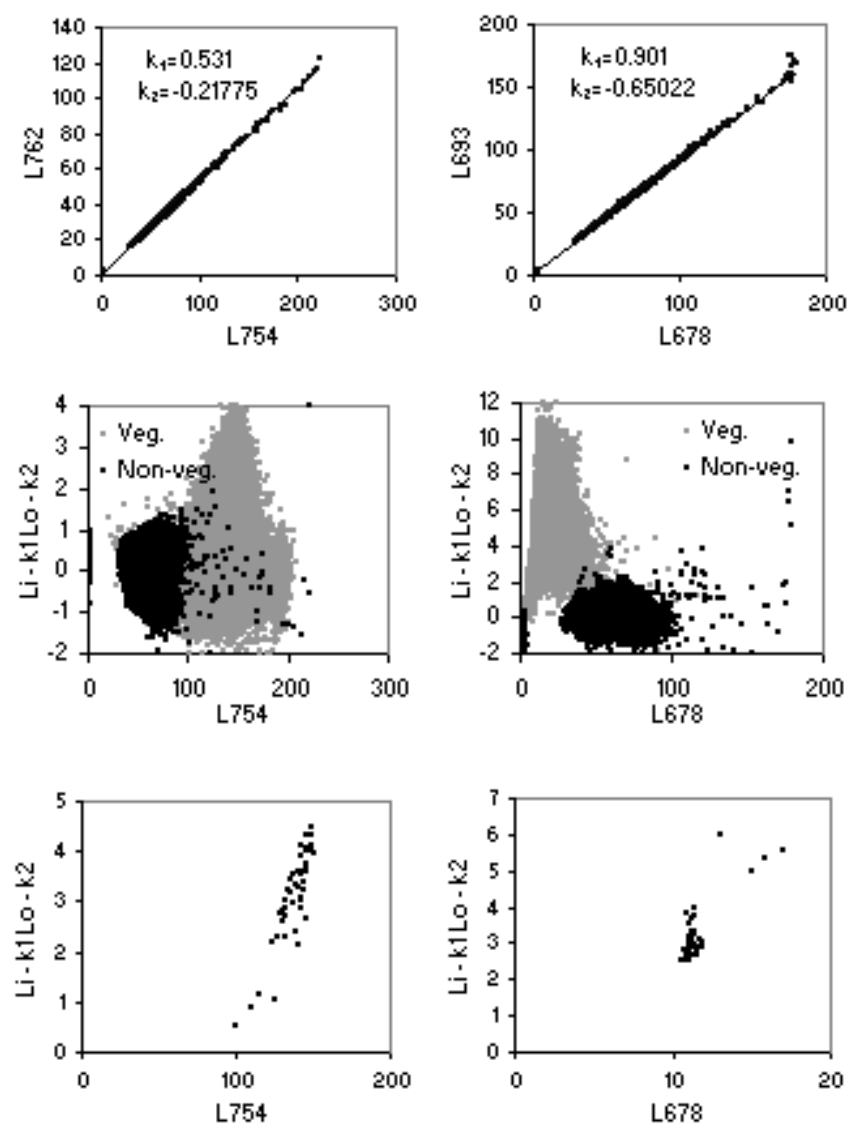

Figure 4. Calculation of $k_{1}$ and $k_{2}$ coefficiemts using non-fluorescing pixels from the airborne CASI image for $762 \mathrm{~nm}$ oxygen band (top left) and $690 \mathrm{~nm}$ band (top right). Fluorescence calculation for non-vegetation (black) and vegetation pixels (grey) for $762 \mathrm{~nm}$ (middle left) and $690 \mathrm{~nm}$ region (middle right). Bottom scatterplots show the calculation of fluorescence from the 48 study plots used in this study with different stress conditions (fluorescence at $762 \mathrm{~nm}$ (left) and $690 \mathrm{~nm}$ (right).
TABLE I. RELATIONSHIPS BETWEEN LEAF-LEVEL FLUORESCENCE MEASUREMENTS AND CASI-ESTIMATED FLUORESCENCE (R)

\begin{tabular}{c|cccccc} 
& $\mathbf{F}_{\mathbf{7 6 2}}$ & $\mathbf{F}_{\mathbf{6 9 0}}$ & $\mathbf{F}_{\mathbf{6 9 0}} / \mathbf{F}_{\mathbf{7 6 2}}$ & $\mathbf{D P i}$ & $\begin{array}{c}\mathbf{R}_{\mathbf{6 8 5}} / \\
\mathbf{R}_{\mathbf{6 5 5}}\end{array}$ & $\begin{array}{c}\mathbf{D}_{\mathbf{7 3 0}} / \\
\mathbf{D}_{\mathbf{7 0 6}}\end{array}$ \\
\hline $\mathbf{B G F} / \mathbf{R F}_{\mathbf{3 6 0}}$ & -0.81 & 0.83 & 0.92 & -0.84 & -0.75 & -0.86 \\
$\mathbf{B G F}_{\mathbf{F}} \mathbf{F F}_{\mathbf{3 6 0}}$ & -0.72 & 0.81 & 0.82 & -0.74 & -0.75 & -0.77 \\
$\mathbf{F R F}_{\mathbf{3 6 0}} / \mathbf{F R F}_{\mathbf{4 4 0}}$ & 0.70 & -0.43 & -0.51 & 0.71 & 0.45 & 0.70 \\
$\mathbf{R F}_{\mathbf{3 6 0}} / \mathbf{R F}_{\mathbf{4 4 0}}$ & 0.69 & -0.42 & -0.50 & 0.70 & 0.43 & 0.69 \\
$\mathbf{F R F}_{\mathbf{3 6 0}} / \mathbf{F R F}_{\mathbf{4 8 0}}$ & 0.71 & -0.43 & -0.51 & 0.71 & 0.45 & 0.70 \\
$\mathbf{R F}_{\mathbf{3 6 0}} / \mathbf{R F}_{\mathbf{4 8 0}}$ & 0.70 & -0.42 & -0.51 & 0.70 & 0.43 & 0.69 \\
$\mathbf{R F}_{\mathbf{4 4 0}} / \mathbf{F R F}_{\mathbf{6 3 0}}$ & 0.71 & -0.59 & -0.69 & 0.64 & 0.61 & 0.70 \\
$\mathbf{R F}_{\mathbf{4 8 0}} / \mathbf{F R F}_{\mathbf{6 3 0}}$ & 0.70 & -0.66 & -0.73 & 0.67 & 0.59 & 0.72 \\
$\mathbf{F R F}_{\mathbf{4 8 0}} / \mathbf{F R F}_{\mathbf{3 6 0}}$ & -0.70 & 0.77 & 0.74 & -0.70 & -0.72 & -0.73 \\
$\mathbf{C}_{\mathbf{a}+\mathbf{b}}$ & 0.80 & -0.84 & -0.78 & 0.88 & 0.79 & 0.88
\end{tabular}

\section{CONCLUSIONS}

Different methods for remote detection of solar-induced chlorophyll fluorescence were presented. Fluorescence infilling at the oxygen bands from radiance CASI data, and optical indices calculated from the reflectance spectra showed good correlations with ground-truth measurements of fluorescence using a multi-wavelength Fluorescent Lidar System. Further research is needed to understand the extent of these results, and to uncouple the effects of canopy structure on the fluorescence estimation from canopy-level imagery.

\section{REFERENCES}

[1] McFarlane, J. C., Watson, R. D., Theisen, A. F., Jackson, R. D., Ehrler, W. L., Pinter Jr., P. J., Idso, S. B., Plant stress detection by remote measurement of fluorescence, Applied Optics, 19, 1980. pp. 3287-3289.

[2] Carter, G. A., Jones, J. H., Mitchell, R. J. and Brewer, C. H., Detection of solar-excited chlorophyll $a$ fluorescence and leaf photosynthetic capacity using a Fraunhofer line radiometer, Remote Sensing of Environment, 55:89-92, 1996.

[3] Buschmann, C. and Lichtenthaler, H. K., Reflectance and chlorophyll fluorescence signatures in leaves, In Applications of Chlorophyll Fluorescence, (Lichetnthaler, H. K., Ed.), Kluwer Academic Publications, Dordrecht, pp. 325-332, 1988.

[4] Zarco-Tejada, P. J., Miller, J. R., Mohammed, G. H., Noland, T. L., Chlorophyll Fluorescence Effects on Vegetation Apparent Reflectance: I. Leaf-Level Measurements and Model Simulation, Remote Sensing of Environment. 74(3):582-595, 2000.

[5] Zarco-Tejada, P.J., Pushnik, J., Dobrowski, S., and Ustin, S.L., Steadystate chlorophyll a Fluorescence detection from canopy derivative reflectance and Double-Peak Red-Edge effects, Remote Sensing of Environment, 84(2), 283-294, 2003.

[6] Maier, S.W., Günther, K.P., Stellmes, M., Remote Sensing and Modelling of Solar Induced Fluorescence, In $1^{\text {st }}$ Workshop on Remote Sensing of Solar Induced Vegetation Fluorescence, 19-20 $0^{\text {th }}$ June, ESAESTEC, Noordwijk, The Netherlands, 2002.

[7] Samson, G., Tremblay, N., Dudelzak, A., Babichenko, S., Dextraze, L., Nutrient stress of corn plants: early detection and and discrimination using a compact multiwavelength fluorescent LIDAR. In Proceedings of the $20^{\text {th }}$ EARSEL Symposium, 14-16 June 2000, Dresden, Germany. 